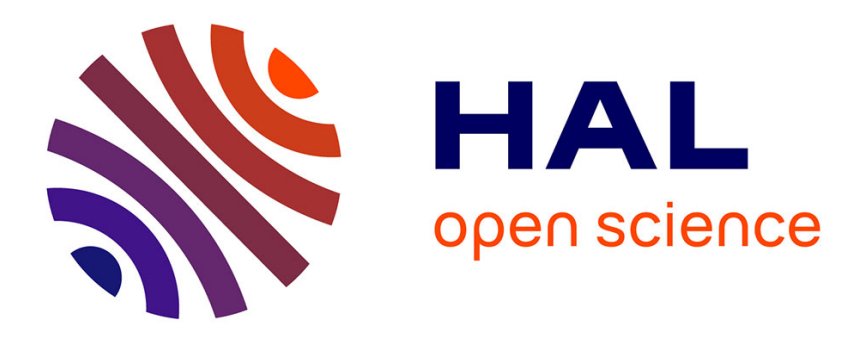

\title{
Lighting Intention Materialization with a Light-Based Parametric Design Model
}

\author{
Vincent Tourre, Francis Miguet
}

\section{To cite this version:}

Vincent Tourre, Francis Miguet. Lighting Intention Materialization with a Light-Based Parametric Design Model. International Journal of Architectural Computing, 2010, 8 (4), pp.507. 10.1260/14780771.8.4.507 . hal-01502786

\section{HAL Id: hal-01502786 https://hal.science/hal-01502786}

Submitted on 6 Apr 2017

HAL is a multi-disciplinary open access archive for the deposit and dissemination of scientific research documents, whether they are published or not. The documents may come from teaching and research institutions in France or abroad, or from public or private research centers.
L'archive ouverte pluridisciplinaire HAL, est destinée au dépôt et à la diffusion de documents scientifiques de niveau recherche, publiés ou non, émanant des établissements d'enseignement et de recherche français ou étrangers, des laboratoires publics ou privés. 


\section{Lighting Intention Materialization with a Light-Based Parametric Design Model \\ Vincent Tourre and Francis Miguet}




\section{Lighting Intention Materialization with a Light-Based Parametric Design Model}

Vincent Tourre and Francis Miguet

\section{Abstract}

How the inverse lighting methods could help the architectural design? We address this issue with an original light-based parametric design model dedicated to the architectural design. This model associates the parametric design approach with the lighting intentions expressed by the architects. It has been implemented thanks to an inverse lighting technique in a tool intended to aid the design of the windows and the shading devices in the early stages of architectural design. This model is used in a performative design approach onto the dome of the Louvre Abu Dhabi museum in order to define the transparency property of the dome. 


\section{Design Context}

The architectural design can be seen as a creative process intended to express an architectural position through the materialization of the designer's intentions. These intentions have to be considered in a holistic approach in order to synthesize all the design constraints and are tightly linked to the performances of the building. As an example, sustainable architecture can be seen as an intention. In order to achieve a sustainable architecture, designers cannot afford to take into account the natural light influence on user comfort and energy consumption. Therefore the performances of the project have to be integrated into the early stages of the architectural design.

The performance-based design concept could help decision-making in giving more information on the performance of the project during the early stages of architectural design. We take a light-based parametric design approach with an inverse lighting model on a real case study in order to address the efficiency of this approach. In the inverse lighting model, the opening itself is considered as an intermediary light source and the inverse simulation process as a research of light source emittance.

The section 2 presents the use of the inverse lighting simulation in the architectural design. In the section 3, our inverse lighting model is presented. Section 4 is dedicated to the experimental case study performed on the Louvre Abu Dhabi museum in order to compute the perforation ratio of the dome covering the museum (Figure I), before to conclude and give perspectives in section 5 .

Figure I. Louvre Abu Dhabi project, exterior view (CAJN)

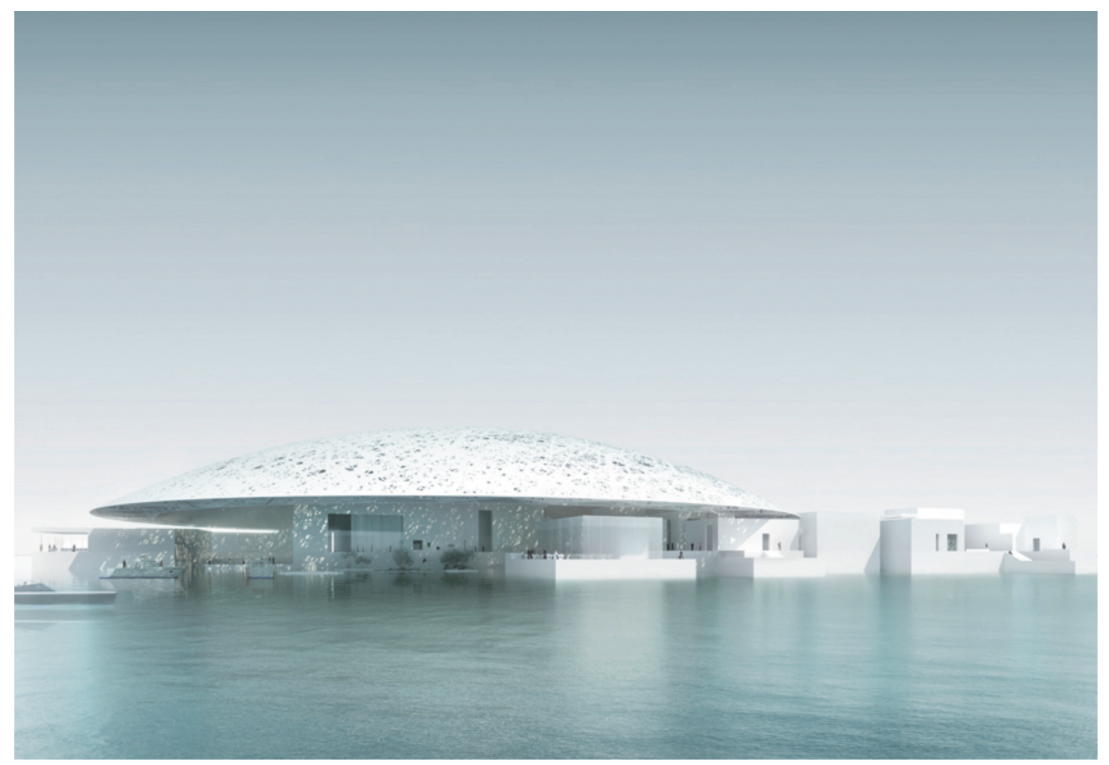

Lighting Intention Materialization with a Light-Based Parametric Design Model 


\section{The Inverse Lighting in Architectural Design}

The architectural design process can be defined as an exploration of the potentialities of the solution space starting from the intentions. Designers need to synthesize a lot of various parameters in order to progress into the design process through a succession of choices.A choice is the result of a search related to a theoretical or graphical reasoning, or a numerical simulation of the building performance in our case. This solution search takes into account the actual state of the project and anticipates its next state. These choices evolve as the project is going on in order to keep the equilibrium of the project constraints.

\section{I. Lighting Performance in the Design}

In the performance-based design approach, the performances of the buildings, revealed by numerical simulations or scale models, are used as guidelines during the design process. Generative tools [ $\mathrm{I}]$ and optimization techniques [2,3] can be used to fully exploit this approach. Nevertheless, the designer has to wait until the end of the design process, or at least the end of the first iteration, to assess the performance of the project.

The key issue is to have an idea about the performances during the early stages of conceptual design, when the buildings are not completely defined and when the designer can still drive his design towards his idea without a loss of time and energy. Going one step further, the building's shape generation process can be directly driven by building performance simulations: this is the performative design concept $[4,5]$. The problem here is precisely that the project is not completely defined: How can we assess the performance of an ongoing designed project? The numerical simulations are useful tools to evaluate the performances of the projects, but how to perform numerical simulations based on a design intention or a to-be-defined building?

The parametric design defines relationships between objects. In this framework, the lighting intentions can be bound to building properties. Therefore a link can be created between the lighting and the form. Using the lighting performance of the designed project to design the form, we are experimenting the performative design approach. The inverse lighting techniques is one of the techniques which put into concrete form the performative design using lighting performance in order to design the building and aid daylight management (Figure 2). The inverse lighting techniques can be used in a performative-design approach, starting from the intention in order to define the building properties, or in a performance-design approach in order to optimize an existing project.

\subsection{Design Tools}

Design tools are the expression means of the intentions and are adapted to the design approach: geometrical design [6], collaborative design [7], and performance-based design [4].As each new tool could bring a new design approach [8], what is the design tool related to the light-based parametric design? 


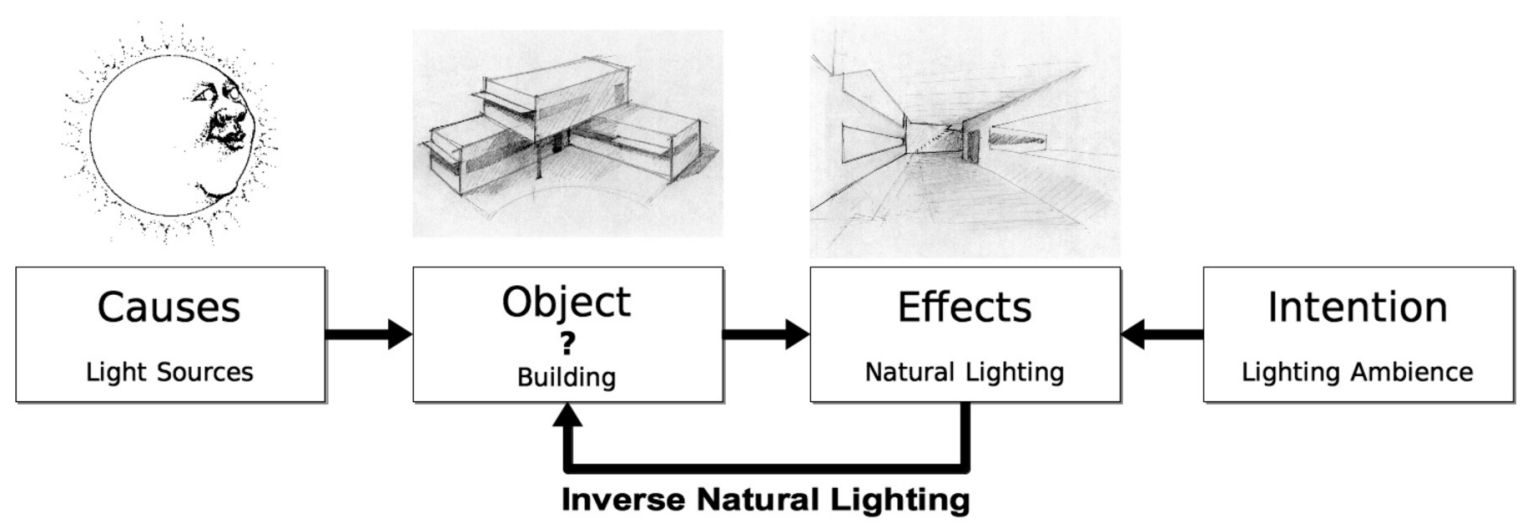

A Figure 2. Light-based parametric design based on inverse natural lighting: the inverse lighting on the designed building is directly driven by the intention
The design tool, digital or not, have to been integrated into the design process and mixed with traditional tools in order to be efficient [9]. The use of a graphic tool to represent a lighting intention results in a drawing with a simultaneous expression of the lighting and the shape, although the intention is only about lighting. Therefore the designer has to use the right tool at the right moment. The right tools to express an intention are, among other thing, texts and drawings. The right one for the light-based parametric design allows working directly with the texts or the drawings describing the intention in order to compute the building properties. Therefore we are interested in the design tools in which the lighting intention can be represented through texts and drawings and then translated into building performances.

\subsection{Posing the Problem of Inverse Lighting}

The design issue is to find out the spatial configuration producing the lighting intention. The intentions have to be processed in order to compute a spatial configuration. The inverse lighting allows this processing in order to find out the source of a phenomenon starting from its effects.

Our problem is to know how the inverse lighting can be integrated into the design process in order to improve the efficiency of the process. This integration is done throught to an original inverse lighting model adapted to the specificities of the architectural design [10] detailed in section 3.This model takes into account natural lighting source and the complex features of lighting intentions.

The insertion of the inverse lighting in the design process allows completing the simulation methods in order to manage globally the relationship between the causes and the effects of lighting. This evolution of the design tools shows the relationship between building and lighting.

We look for the causes producing a desired lighting. As the lighting sources are known (sun, sky, and reflections from surroundings) this model computes the properties of the building. Therefore the designer will be able to understand the impact of his lighting intentions onto the architectural project.

We consider that we cannot find the optimal solution with the inverse lighting model, mainly because all the design parameters are not integrated 
in this model. Therefore, the inverse lighting model has to answer to the lighting problem and the results have to be interpreted by the designers in order to integrate all the other constraints.

\subsection{State of the Art}

Designing shapes from lighting data is a well-known problem in the computer graphics community since seminal works of Poulin and Fournier [ $\mathrm{I} \mathrm{I}$.

Previous works can be classified following the inverse problem type [12] according to whether the required element depends on the scene geometry -inverse geometry [I], the reflectance properties of surfaces-inverse reflectance [3], or the position and intensity of light sources-inverse lighting $[2,3]$. For a more complete review of these inverse problems we refer to [13]. Although numerous methods allow the inversion of the lighting simulation and some methods are dedicated to the inverse natural lighting in architecture, no method allows working with complex features such as complex geometry, graphic lighting intention or surroundings influence.

The light-based parametric design can be focused on the building hull, which filters the natural light, or on the reflectance properties of the building materials, which influence the light transport. The problem addressed in this paper is to compute shape and light transmission properties of building openings from natural lighting intentions. This is a combination of an inverse geometry problem as we are looking for scene geometry, and an inverse lighting problem as we are looking for material properties (i.e. transparency) or light source visibility. Therefore this problem is not clearly identified in the inverse rendering framework as an inverse geometry problem or an inverse lighting problem. In the next section we explain our approach to address this issue.

\section{The Inverse Natural Lighting Model}

\section{I. Focus on the Light Filter}

The association of a lighting intention with an ongoing project is considered as setting up a relationship between the outdoor environment and indoor lighting. This relation generates an opening potential and the inverse lighting is one of the means to reveal this potential.

The building hull is considered as the pivot of the natural lighting phenomenon [14]. The inverse lighting principle is applied through the evaluation of the similarities between the lighting intention and the lighting provided by some elements composing the building hull. This comparison allows computing the influence of an element of the building hull in the materialization of the lighting intention.

As we are interested in lighting coming from the outside, the problem is to know if the lighted surface can or cannot see the light sources. This visibility is determined by the building geometric properties so the inverse problem is an inverse geometry problem. But looking for geometrical properties is very complex as the combinations of size, shape and position are numerous. 
Nevertheless, if we consider the building hull as a light filter then the inverse problem is an inverse lighting problem. A filter can be seen as a set of intermediary light sources. These intermediary light sources have an anisotropic feature which is essential in the solving of the inverse problem and which has not been taken into account in previous works. The emittance property of these intermediary light sources is bound to the transparency properties of the filter. Therefore the inverse problem can be seen as an emittance research of these anisotropic light sources.

\subsection{An Inverse Lighting Approach}

Tourre [10] has proposed an emittance research approach based on a pinhole model and an image distance measurement to compute the opening properties. This inverse lighting model computes the opening properties in a given space from the lighting intentions of the designer. These intentions can describe complex features with a heterogeneous distribution of light coming from the sun, the sky or the reflections of the surroundings. This model is based on a meshing of the faces filtering the natural lighting (i.e. the faces where the openings or sun shading devices can be placed). Each patch is considered as a potential anisotropic light source and called virtual light source (Figure 3). This model has been implemented in the prototype called EEL: Espace En Lumière.

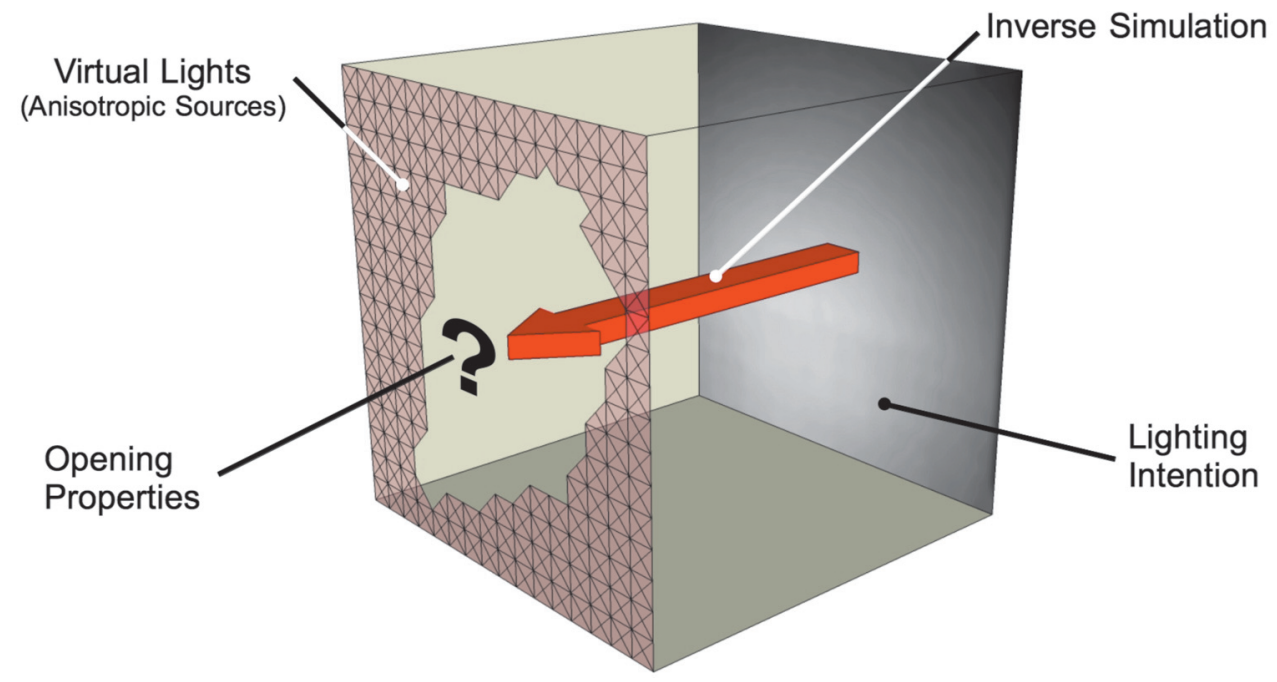

A Figure 3. Inverse lighting model principle
The inverse natural lighting model contains three steps (Figure 4):

- The generation of virtual light sources: the lighting contribution of each virtual light is computed with lighting simulation in order to obtain lighting from the sky and the surrounding passing through each light source.

- The evaluation of virtual light sources against the designer intention: each virtual light source is evaluated in order to compute its influence onto the lighting and to build an evaluation map of the filtering surface. 
- The interpretation of the evaluation map: the evaluation map is considered as the input data at the interpretation step. The computed solution is intended to be a starting point for the architect in his daylight design.

As the natural lighting is tightly linked the temporal dimension, time handling is an essential feature of the inverse lighting model. Our model can compute an evaluation map from several time instants. Each time instant can have his own lighting intention or share a lighting intention with others depending on the architect.

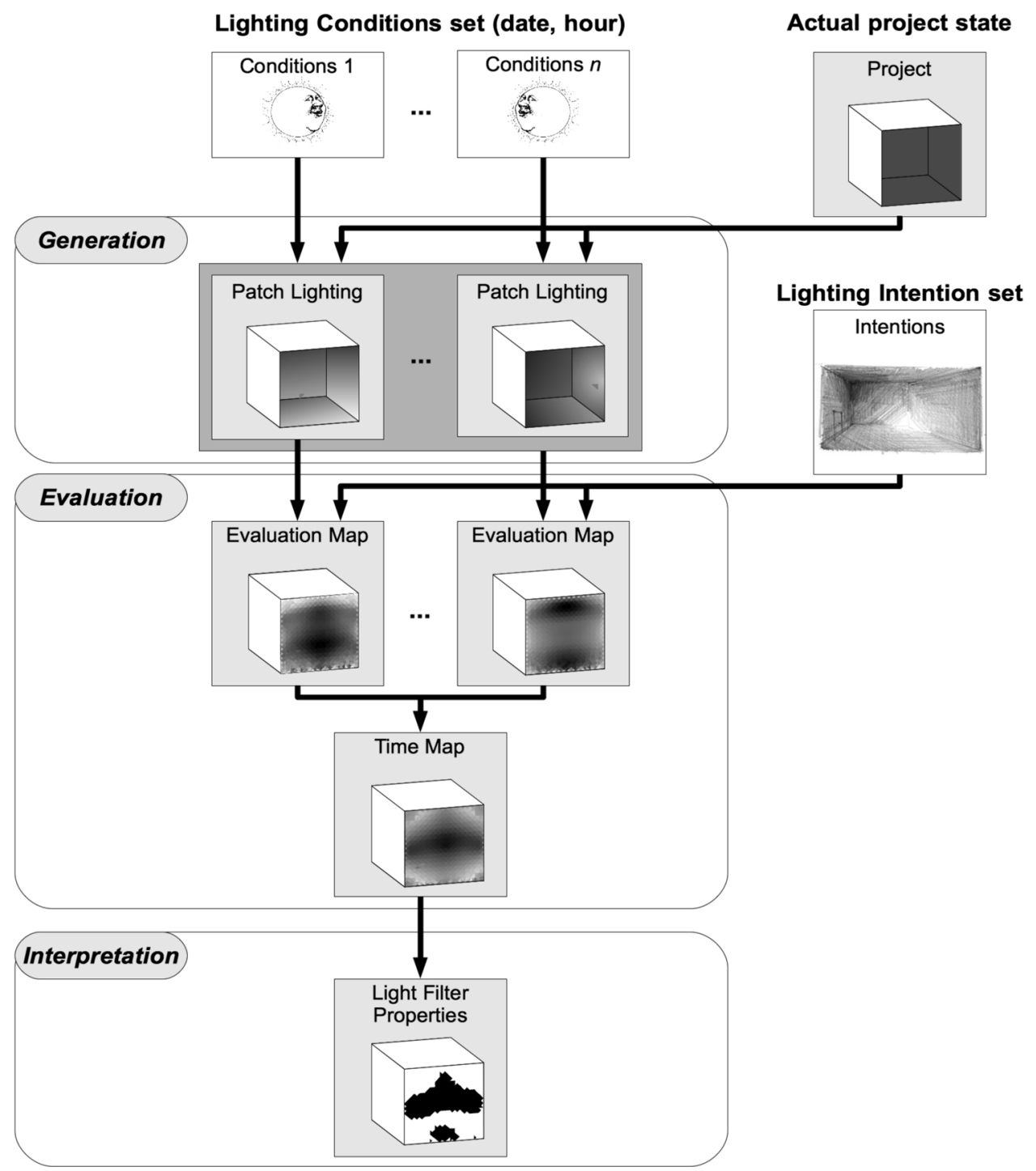

$\Delta$ Figure 4. The different steps of the inverse lighting model 


\section{Case Study:The Louvre Abu Dhabi}

We had a great opportunity to experiment the previous inverse lighting model in the very early stages of architectural design of the Louvre Abu Dhabi museum by Atelier Jean Nouvel (AJN). This museum is a vernacular city under a 180 meters wide protective dome that covers partially the city (Figure I). The design team (Hala Wardé/Ateliers Jean Nouvel) wants to give a special attention to the natural lighting management under the dome.

Through this study, our goal was to show that we were able to support the design team and associated engineers: Buro Happold and TransSolar.

The dome is actually composed by a superposition of cladding forming a large sun-shading device inspired by the mashrabiyas. The problem was to define the perforation ratio of the dome in order to filter the sunlight and delineate specific outdoor areas. Therefore this is not strictly speaking a case of indoor lighting, as the space is not closed. The key idea is a variation of the perforation ratio, apparently randomly, but actually materializing the lighting intentions expressed by the team:

- "Jean Nouvel formulated the main goals for the outdoor spaces with:

- A rain of light

- Variation of light levels and temperatures on the piazza

- Comfort is a part of the design." [15]

This text intentions has been interpreted in order to produce pictures of these intentions (Figure 5). These intentions have also been associated with a temperature map under the dome in order to take into account the user comfort. Therefore the challenge was to handle simultaneously the vision of the architect and the building performances. During the inverse

Figure 5. A picture of the lighting intentions under the dome (CAJN)

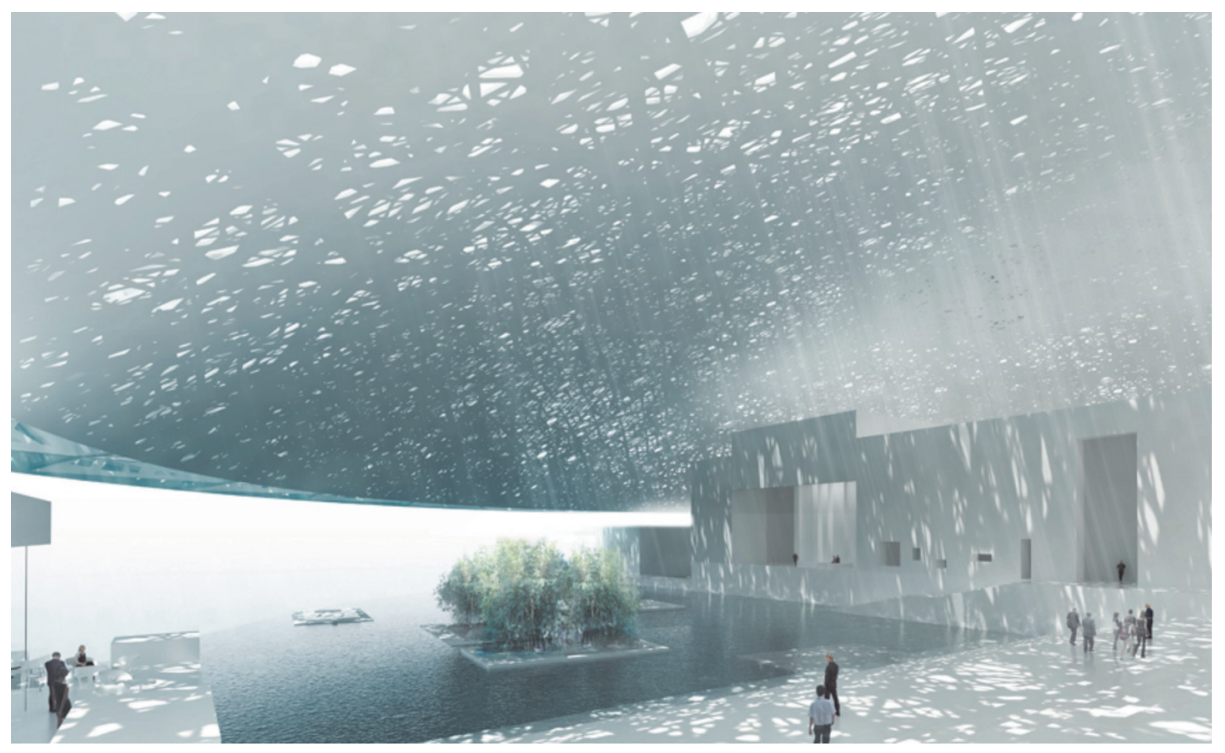

Lighting Intention Materialization with a Light-Based Parametric Design Model 
lighting process, these constraints have been translated into a natural lighting map in order to be processed by the inverse lighting model.

The steps and the associated tools of the lighting study can be summarized as follow (Figure 6):

- Preliminary lighting simulations on 3D Model with Solene [16], with and without the dome, on 2I March, June and December in order to aid the description of lighting intentions,

- Definition of the lighting intention map, which is the starting point in order to perform inverse lighting simulations,

- Inverse natural lighting with the EEL prototype [10] in order to compute the influence of the dome elements onto the outdoor spaces of the museum, and Computing the dome perforation ratio,

- Checking the dome configuration with a forward lighting approach.

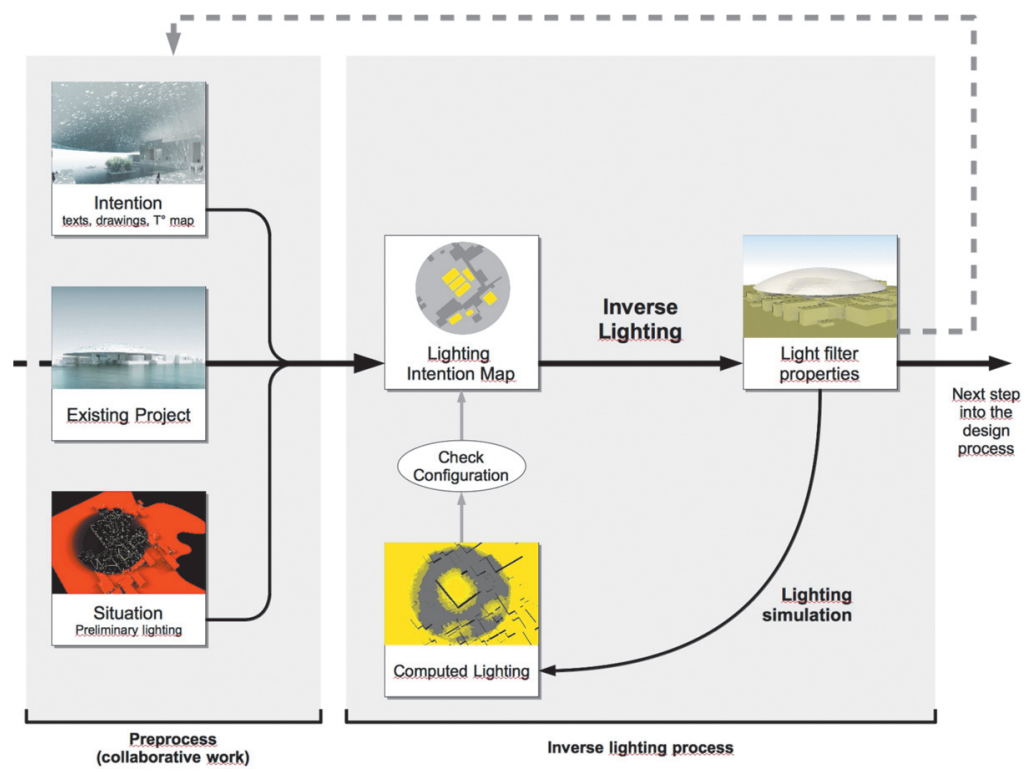

\section{I. Preliminary Lighting Study}

The preliminary lighting study showed the lighting potential of the city under the dome and the shading potential of the dome. This study defined the lighting range and therefore the value bounds of the lighting intention which are necessary to aid the lighting intention map definition and to perform inverse lighting.

\section{Irradiance Values}

Irradiance values on a horizontal surface for a $24^{\circ}$ north latitude have been computed with Solene (Table I and Figure 7) in order to compute the lighting variation during the day. As there is a lot of sunny days in Abu Dhabi, these values can be used as a work basis:
Figure 6. Steps of the lighting study 


\begin{tabular}{|c|c|c|c|c|c|c|c|c|c|c|c|c|c|}
\hline & $6: 00$ & 7:00 & $8: 00$ & $9: 00$ & $10: 00$ & I I:00 & $12: 00$ & 13:00 & $14: 00$ & 15:00 & $16: 00$ & 17:00 & $18: 00$ \\
\hline March & 3,9 & 150,48 & 406,7 & 652 & 842,7 & 959,2 & 998,7 & 959,8 & 841,7 & 649,7 & 405,2 & $150, \mid$ & 3,9 \\
\hline June & 79,9 & 308,9 & 560,6 & 786,7 & 959,9 & 1067,8 & 1102,9 & 1067,8 & 960,1 & 788,2 & 562,7 & 310 & 80,2 \\
\hline Dec. & 0 & 14,5 & 174 & 377,7 & 546,2 & 652,8 & 689,8 & 655,4 & 548 & 377,6 & 173,2 & I4,4 & 0 \\
\hline
\end{tabular}

A Table I. Incident global irradiance (sun and sky) during the day $\left(\mathrm{W} / \mathrm{m}^{2}\right)$

Figure 7. Global irradiance $(\mathrm{W} / \mathrm{m} 2)$ between 6 a.m. and 6 p.m. on a horizontal surface for a $24^{\circ}$ north latitude

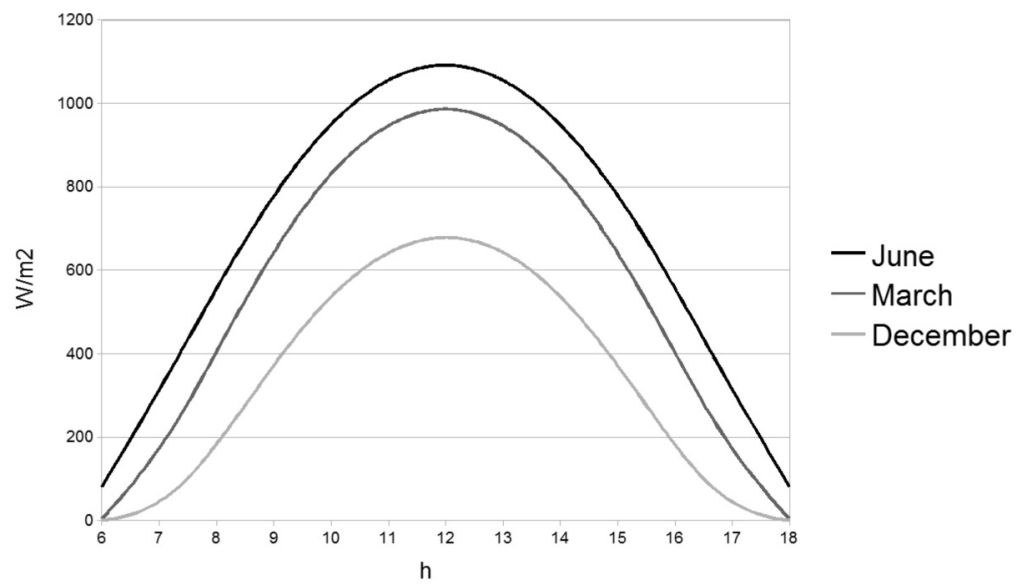

According to many authors $[17,18]$, we consider a luminous efficiency of $110 \mathrm{~lm} / \mathrm{W}$. Therefore the maximal illuminance values are around I $10000 \mathrm{lux}$ on 21 March, 120000 lux on 21 June and 76000 lux on 21 December. These values will be used to define the lighting intention map.

\section{Sunlight Duration}

The sunlight duration values computed without the dome show the cast shadows (Figure 8, left column). The plaza and the water area are partially protected by the buildings, even in June although the sun is very high in the sky (height $85^{\circ}$ on 21 June at $12 \mathrm{~h} 00$ ).

The sunlight duration values computed with the dome show the potential protection provided by the dome to the museum (Figure 8, right column). Although, the sun is moving during day and seasons, this protection remains well positioned and efficient over the main museum buildings because the dome is very close to the building roofs.

The cast shadow of the dome is moving very slowly on 21 June during midday, therefore a lighting configuration computed from the lighting on 2I June will be efficient during all summer time. On the contrary, the cast shadow of the dome is moving much more during December, and a lighting configuration computed from the lighting configuration on 21 December will be efficient few hours during few days during winter. As a consequence, the lighting on $2 \mathrm{I}$ June is taken a work basis, while keeping in mind the impact of the dome configuration on lighting during winter. 

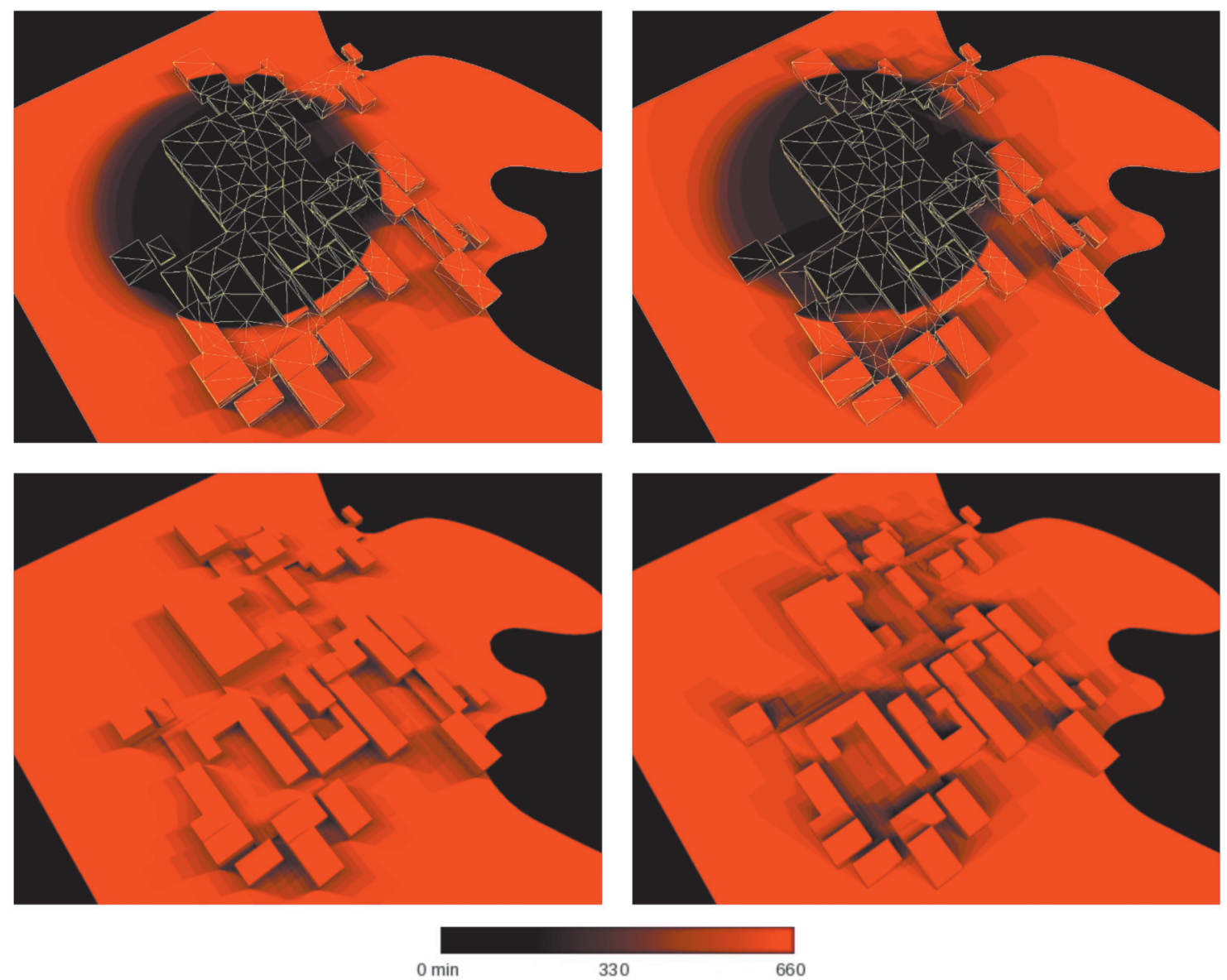

\subsection{Lighting Map Definition}

The definition of the lighting map is essential to the inverse lighting process. This map can be defined by the architect on his own or by a collaborative process, and can depends on other parameter. In this case study, the lighting intention map has been defined with collaborative process between the architects, the engineers and the researchers starting from the lighting intentions (text and pictures) and the temperature map.

The lighting intention map contained three areas: Plaza, Galleries, Water and other buildings (Figure 9). The illuminance levels in lux were based on the report from TransSolar (Schuler 2008), meetings with the Buro Happold engineers and the preliminary lighting studies. The galleries were intended to have a daylight factor of $10 \%$. The plaza was intended to be well protected while the water surface and the others buildings were slightly less protected. These intentions are very complex because they are very contrasted. Moreover the lighting are expected all over the year at $12 \mathrm{~h} 00$ which is quite difficult to achieve due to the different sun positions according to the seasons.
$\Delta$ Figure 8. Sunlight duration without (left column) and with the dome (right column) on 2l/06 (top line) and 2I/I2 (bottom line) 
Figure 9. The lighting intention map under the dome

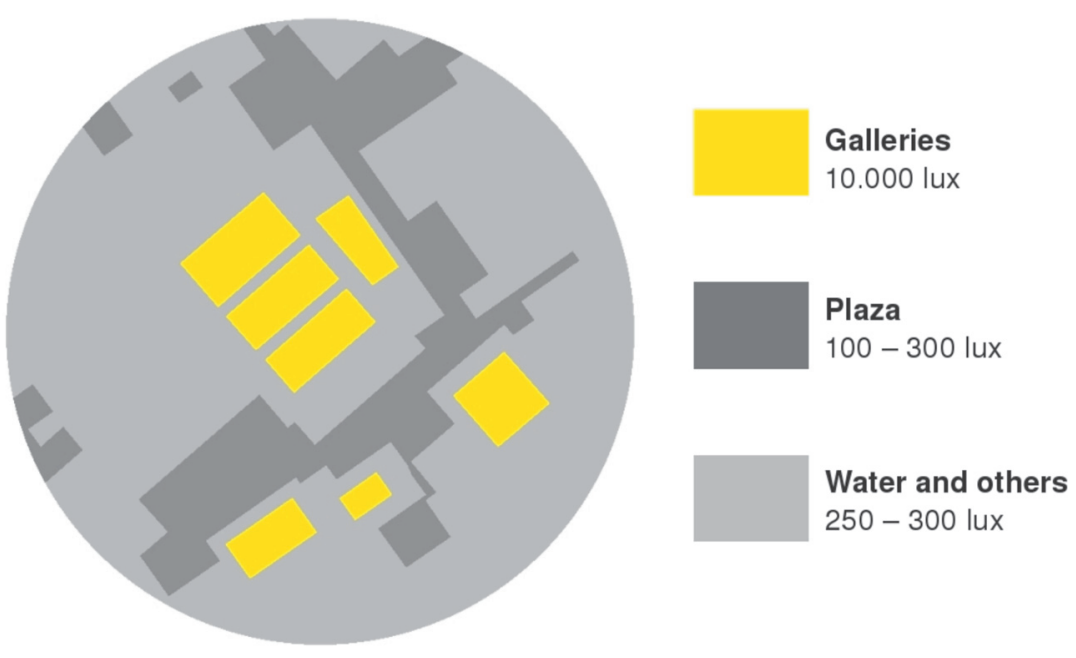

\subsection{Dome Perforation Computing}

The lighting intention map has been processed through the three step of the inverse lighting model: generation, evaluation and interpretation.

\section{Virtual Light Source Generation}

In this study the light filter is the protective dome, therefore all the potential light sources are contained into this $25000 \mathrm{~m}^{2}$ dome. The dome was meshed in 1028 triangles as a triangle mesh is needed by the EEL prototype, and each triangle patch was considered as a virtual light. The lighting produced by each virtual light was generated using the pin-hole model of the EEL prototype taking into account the sun and the sky. The surroundings were not take into account as the light filtered by the dome is not influenced by the surroundings.

\section{Virtual Light Source Evaluation}

The goal of the evaluation step is to compute the evaluation maps comparing the lighting intentions against the lighting provided by each virtual light. The lighting intention map has been separated in order to compute the inverse lighting more accurately and the others building were put aside for the simulation. Therefore the influence of the dome elements onto the museum was computed for each area (Figure 10).

\section{Interpretation of the Evaluation Maps'}

The evaluation maps were interpreted in order to compute the perforation ratio of the dome. The light levels given in the lighting intentions map allowed converting the influence of the virtual lights into the perforation ratio of the each patch. The perforation ratio of each patch was computed with a weighted sum of the desired values from Figure 8. The weights were 


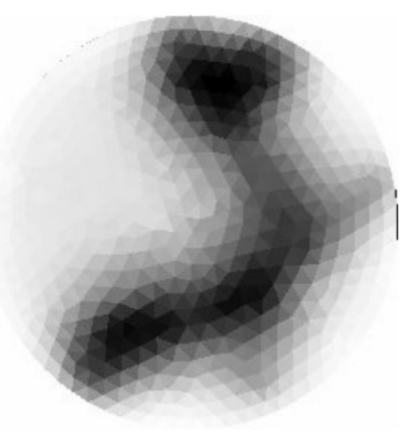

found in the corresponding evaluation map (Figure 9). The final perforation ratio ranges from $2 \%$ to $8 \%$ over the "natural lighting" areas, the galleries which needs around 10.000 lux, and from $0.1 \%$ to $1 \%$ over the protected areas (Plaza, Water surface) (Figure II).

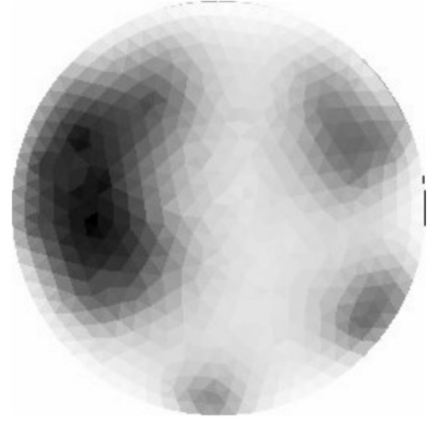

$\Delta$ Figure 10. Evaluation maps of the dome (l. to r.) plaza, galleries and water areas

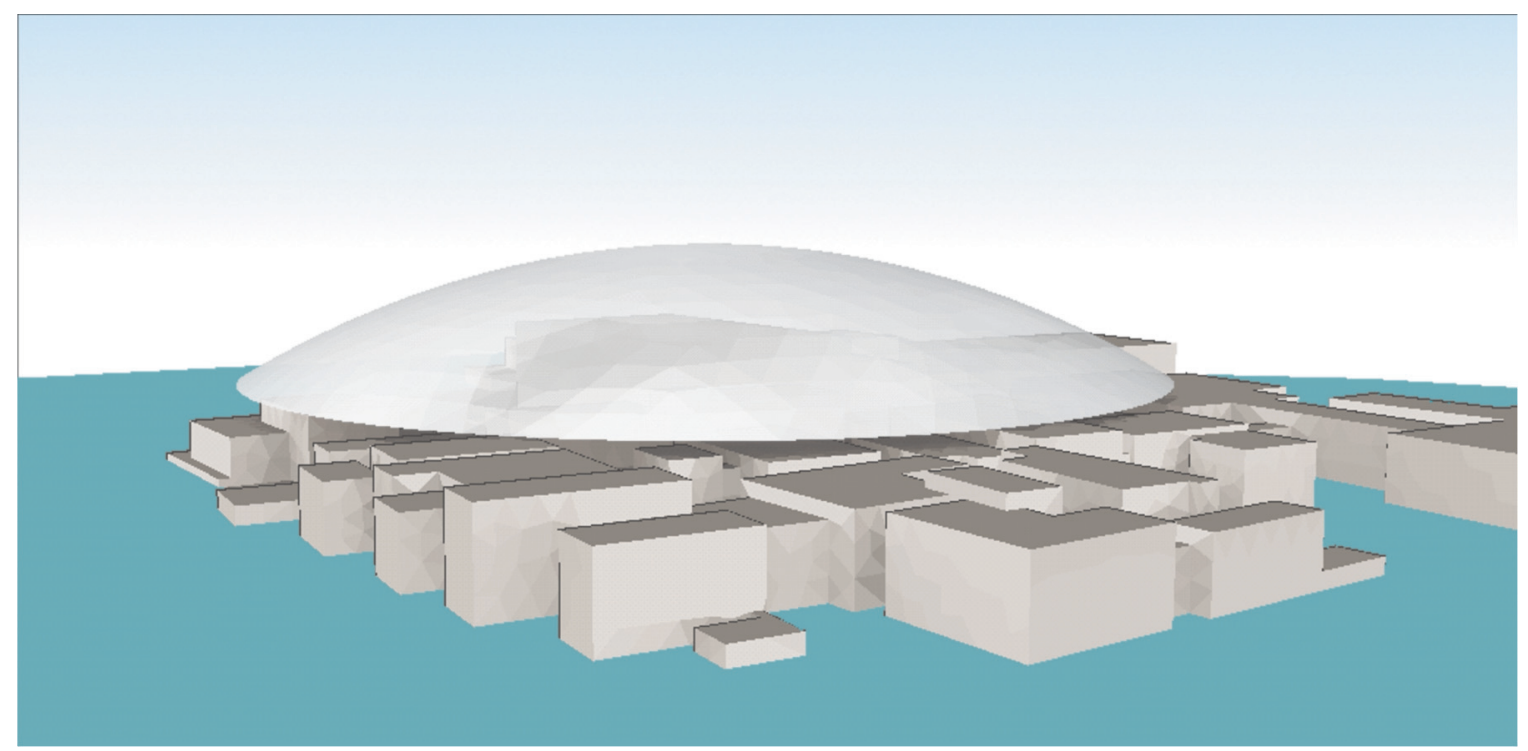

\subsection{Forward Lighting Simulation with Solene}

$\Delta$ Figure II.The dome perforation

In order to check the results of the inverse lighting computations, a forward natural lighting simulation was performed with Solene (Figure 12). As the perforation size is small compared to the size of the dome, the perforation values can be considered as a transparency coefficient in these computations.

Although the inverse model takes into account the direct light (sun and sky), the reflections has been added to the final lighting simulation with the radiosity engine embedded in Solene in order to assess the total lighting. According to the design team instructions, the lighting reflections were computed with a reflection coefficient of $30 \%$ for the plaza, the buildings and the dome inner face, which correspond to a light grey tile. A reflection coefficient of $5 \%$ was used for water surface reflections. 

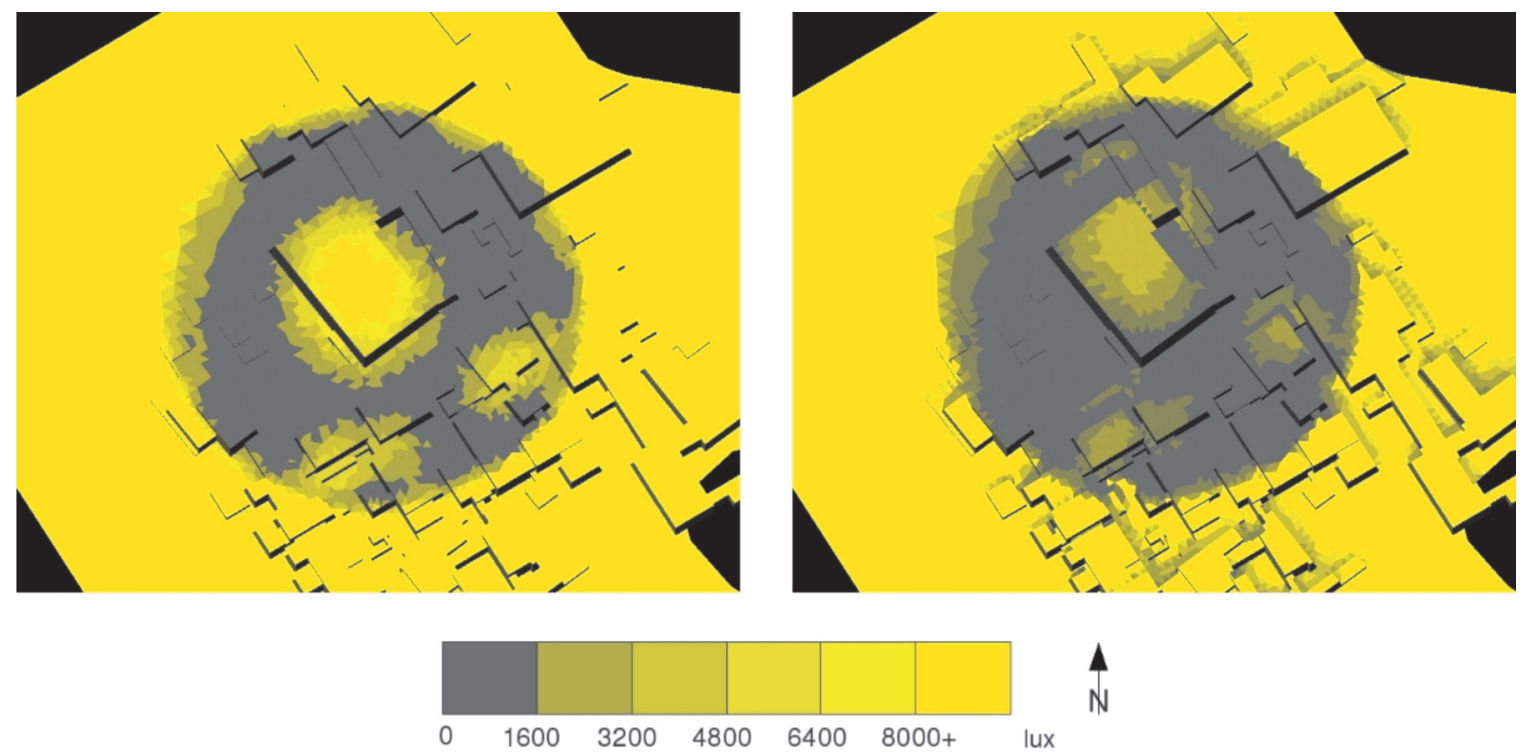

$\Delta$ Figure 12. Global illuminance on $2 \mathrm{I} / 06$ (left) and 2I/I2 (right) at $12 \mathrm{~h} 00$
The roof of the galleries buildings has high illuminance values while the plaza, the water surface and the other buildings are well protected during summer and winter. The difference between the plaza and the water area is not visible because the desired value ranges are very close (100-300 lux and 250-300 lux) compared to the galleries expected value ( 10000 lux).

The main idea of contrast between the galleries area and the others areas is well represented. We manage to get a contrast from 10000 lux in bright areas to around I 000 lux or less in darker areas. The mean squared error between the lighting intention and the lighting simulations with our dome configuration is 14.7 in summer and 19.1 in winter, which represent $5.7 \%$ and $7.4 \%$ of the maximum error value, respectively. These errors were acceptable at this stage of conceptual design and corresponded to the expectation of the team.

\subsection{Comments on the Case Study}

Although the inverse lighting model has been designed to deal with indoor natural lighting, it fits well to outdoor natural lighting as soon as the lighting filter is well identified: the dome is this case study. Concerning the perforation ratio of the dome, the main idea of contrast expressed through the lighting intention maps is respected. The proposed perforation values have been converted in transparency coefficient in order to check the dome configuration with Solene simulations. These simulations show that the proposed perforation ratio allows approaching the lighting intentions. Therefore, we confirm the originality and the interest of this model, which is able to materialize the complex intentions of the architect.

As we said in the section 2, the result of the inverse lighting has to be interpreted by the designers. Therefore, the proposed perforation ratio 
could be used as a basis by the design team in order the compute the geometry of the dome parts as the project is going on. As we aid the definition of the geometric properties of the dome elements directly from physical simulation, this study could be considered as a performative design approach.

The main problem in this kind of study remains that the inverse lighting model still needs preliminary lighting studies in order to be efficient. Another drawback is that the inverse lighting computations only take into account the direct lighting without reflections, so the lighting coming from the reflections has to be anticipated by the architect and design team when defining the lighting intention map.

Besides this, the use of our model on a real case study with the feedback of the design team gives us a very interesting point of view on the model and its limits. In order to meet the expectations of the architects, this model still needs some improvements in order to be more efficient. As an example, the exchange of the simulation data (geometric model, simulation results, etc.) has been a real time consuming task so we have to reach an integrated design approach in order to take into account the BIM models and to be fully integrated into the design process. Moreover, digital design systems are characterized by three elements: the geometric model, the evaluation process and the interactivity of the design (Oxman 2008). We manage to get the first two points into our model. Now the interactivity has to be integrated in our next research in order to fulfil the digital design systems requirements.

\section{Conclusion}

This work is intended to use a light-based parametric design framework implemented in a tool that is ready to use by architects and engineers. The inverse lighting model integrates anisotropic light sources and is able to define opening properties from a heterogeneous lighting distribution. The model has been tested and the results have demonstrated this inverse lighting model can be an aid to architectural design.

We use the inverse design not only to tune some details but also to reach a specific goal during the early stages of conceptual design through several steps: expression, translation, processing and interpretation.

The integration of an inverse natural lighting model enhances the computer-aided design tools in order to aid the definition of the light filter properties starting from natural lighting description. As a consequence the designer is able to understand the impact of his lighting intentions onto the architectural shape. Therefore we begin addressing the issue of the role of the inverse lighting in architectural design:This is a useful tool that could bring a new design approach into the performative design framework, but we have to perform more studies to answer more precisely to this question. 
Where further works are concerned, others physical phenomenon can be integrated into the design process. As an example, a heat simulation could be necessary to check the impact of the proposed configuration on the user comfort and energy consumption [19]. So we need to develop further models and tools that encompass the architectural design goal, the performance-based design goal and an innovative merging of both.

\section{Acknowledgements}

The study on the dome of the Louvre Abu Dhabi museum has been supported by Ateliers Jean Nouvel and Buro Happold.

\section{References}

I. Mahdavi, A. and Berberidou-Kallikova, L.,A generative simulation tool for architectural lighting, 4th International Conference on Building Simulation, 1995.

2. Costa,A.C., Sousa, A.A. and Ferreira, F.N., Lighting design: A goal based approach using optimization, in: Rendering Techniques, 1999, 317-328.

3. Kawai, J.K., Painter, J.S., and Cohen, M.F., Radioptimization: goal based rendering, in: SIGGRAPH '93: Proceedings of the 20th annual conference on Computer graphics and interactive techniques, ACM, 1993, 147-154.

4. Kolarevic, B. and Malkawi, A.M. (eds.), Performative Architecture: Beyond Instrumentality, Spon Press, New York, 2005.

5. Oxman, R., Performance-based design: Current practice and research issues, International Journal of Architectural Computing, 2008, 6(I), I-I7.

6. Guéna, F. and Untersteller, L., Towards a sketching tool for architect: 3D reconstruction of polyhedrons, in: Bourdakis, V. and Charitos, D., eds., 24th eCAADe Conference Proceedings: Communicating Space(s), Education in Computer Aided Architectural Design in Europe and School of Engineering, University of Thessaly, 2006, I32-135.

7. Halin, G., Bignon, J., Scaletsky, C., Nakapan, W. and Kacher, S., Three approaches of the use of image to assist architectural design, in: CAADRIA 2003 Proceedings, 2003, $183-198$.

8. Madrazo, L., Computers in architectural design: Going beyond the tool, in: ACADIA 98 proceedings: Do Computers Make a Difference in Design Studio?, 1998, 44-57.

9. Stannord, S., Computer in design: Exploring light and time, ACADIA 98 proceedings: Do Computers Make a Difference in Design Studio?, 1998, 26-35.

10. Tourre,V., Martin, J.-Y., and Hégron, G., An inverse daylighting model for CAAD, SCCG '08: Proceedings of the 24th Spring Conference on Computer graphics, Comenius University, Bratislava, 2008, 95-102.

II. Poulin, P. and Fournier, A., Lights from highlights and shadows, Proceedings of the 1992 symposium on Interactive 3D graphics, 1992, 31-38.

12. Marschner, S.R., Inverse rendering in computer graphics, PhD Thesis, Cornell University, 1998.

13. Patow, G. and Pueyo, X., A Survey of Inverse Surface Design From Light Transport Behavior Specification, Computer Graphics Forum, 2005, 24(4), 773-789.

14. Millet, M.S. 1996, Light revealing architecture, John Wiley and Sons, 1996.

15. Schuler, M. and Billard, A., Louvre Abu Dhabi-Report concept phase, TransSolar, 2008.

16. http://solene.cerma.archi.fr/wiki/doku.php [27-7-20I0]. 
17. Baker, N.V. and Steemers, K.A., Daylight design of buildings, James and James Ltd., London, 2002.

18. Fontoynont, M., Daylight performance of buildings, James and James Ltd, London, 1998.

19. Caldas, L. and Norford, L., Architectural constraints in a generative design system, in: Interpreting energy consumption levels, Seventh International IBPSA Conference, 200I, I397-1404. 